\title{
ECOESCOLA: DO INDIVIDUAL AO COLETIVO
}

\author{
Letícia Hoehne ${ }^{1}$
}

\begin{abstract}
Resumo: $O$ presente artigo visa instigar o quão importante se faz inserir a Educação Ambiental na sala de aula e estimular a comunidade escolar a se auto questionar sobre suas atitudes, assim como levantar possibilidades de melhorar nesta questão. Para isso, foi realizada uma pesquisa de campo na escola I.E. São José e pesquisa bibliográfica. Posteriormente, as respostas foram analisadas e as sugestões classificadas. Conclui-se que é essencial popularizar o contato com a Educação Ambiental, pois cada um fazendo a sua parte, obter-se-á o bem coletivo.
\end{abstract}

Palavras-chave: Cooperação. Meio ambiente. Sustentabilidade.

\section{ECOESCOLA: FROM INDIVIDUAL TO COLLECTIVE}

\begin{abstract}
This article aims to instigate how important it is to insert Environmental Education in the classroom and to stimulate the school community to question itself about its attitudes, as well as to raise possibilities to improve on this issue. For that, a field research was carried out at the Instituto Estadual São José, in the city of Soledade / RS, and bibliographic research. Subsequently, the responses were analyzed and the suggestions were classified. It is concluded that it is essential to popularize the contact with Environmental Education, because each one doing his part, will get the collective good.
\end{abstract}

Keywords: Cooperation. Environment. Sustainability.

\section{INTRODUÇÃO}

O ambiente escolar é um perfeito local de aprendizado, não somente dos conteúdos curriculares estabelecidos pelas Diretrizes Curriculares Nacionais (LDB, 1996), mas também de aprendizado social. Neste caso, ressalta-se a importância do coletivo, da cooperação uns com os outros, do bem comum, do dividir, compartilhar, em suma, da importância de conviver e usufruir em conjunto do meio onde estão inseridos (ENGUITA, 1995).

1 Graduada em Ciências Biológicas - LP pela Universidade de Passo Fundo, Especialista em Biologia da Conversação da Natureza pela Universidade de Passo Fundo, Especialista em Educação Ambiental pelo Centro Universitário Barão de Mauá, São Paulo. Professora de Ciências na Escola Estadual de Ensino Fundamental Justino Alberto Tietboehl, no município de Torres/RS. E-mail do autor: letícia. hoehne@yahoo.com.br. 
Neste ínterim, cabe salientar que os recursos que a escola oferece também devem ser utilizados no coletivo. Pode-se citar como recursos oferecidos pela escola: o livro didático, a classe, a cadeira, o quadro negro, o computador, a merenda, a água para os banheiros, e muitos outros. Com isso, questiona-se: quais dos itens citados anteriormente necessitam de recursos naturais para existirem? Direta ou indiretamente, a resposta é: todos!

Dessa forma, a educação ambiental se faz de fundamental importância para a formação de um cidadão crítico e consciente da importância da conservação dos recursos naturais para o bem estar de todos da sociedade (CARVALHO, 2006). Assim, o presente estudo visa identificar as possibilidades de tornar a escola Instituto Estadual São José, no município de Soledade/RS, em uma escola mais ecologicamente correta, estimulando o fazer individual para o bem coletivo.

\section{A EDUCAÇÃO AMBIENTAL}

O ser humano faz parte da natureza, e, assim como todos os demais seres vivos, interage com os recursos naturais na busca por satisfazer as suas necessidades. No entanto, as necessidades humanas não têm limites, e a exploração de recursos naturais só tem aumentado com o passar do tempo.

Herculano (1992, p.22) aponta que a "Revolução Industrial intensificou a exploração da natureza pelos homens. A consolidação da ética antropocêntrica torna a natureza e a cultura humanas, que antes caminhavam juntas, duas coisas distintas e sem ligação".

Com a descoberta de que os recursos naturais são esgotáveis, o ser humano começou a preocupar-se. Assim, alguns utilizaram a sua capacidade racional para iniciar uma ciência nova e extraordinária: A Educação Ambiental.

O ano de 1972 foi histórico para o movimento ambientalista mundial, quando as discussões sobre o tema culminaram na Primeira Conferência Mundial do Meio Ambiente Humano, em Estocolmo, na Suécia, convocada pela Organização das Nações Unidas (ONU) sobre o grande impacto causado pelo relatório do clube de Roma sobre o uso dos recursos naturais disponíveis no planeta. A partir desta conferência, a Organização das Nações Unidas para Educação, Ciência e Cultura (Unesco) assumiu a organização de discussões regionais e internacionais de educação ambiental (TOZONIREIS, 2004).

De acordo com a Primeira Conferência Intergovernamental sobre Educação Ambiental, realizada em 1977 em Tbilisi, Georgia (ex URSS) a educação ambiental é considerada um processo constante, no qual toda sociedade adquire consciência sobre o ambiente e, Dias (1992, p.116) destaca que dessa forma se "obtém os conhecimentos, os valores, as habilidades, as experiências e a determinação que os tomam aptos a agir 
individual e coletivamente para resolver problemas ambientais presentes e futuros (DIAS, 1992, p. 116).

Lima (2009, p.2) refere-se que a Educação ambiental no Brasil se constituiu como um campo de conhecimento e de atividade pedagógica e política a partir das décadas de 1970. A educação ambiental "nasceu como um campo plural e diferenciado que reunia contribuições de diversas disciplinas científicas, matrizes filosóficas, posições políticopedagógicas, atores e movimentos sociais" (LIMA, 2009)

Nesse ínterim, Jacobi (2003, p. 59) ressalta que "tomando-se como referência o fato de a maior parte da população brasileira viver em cidades, observa-se uma crescente degradação das condições de vida, refletindo uma crise ambiental" (JACOBI, 2003, p. 59). Isto remete a uma necessária reflexão sobre os desafios para mudar as formas de pensar e agir em torno da questão ambiental numa perspectiva contemporânea. Leff (2001, p. 3) discorre que

\begin{abstract}
[...]resolver os crescentes e complexos problemas ambientais e reverter suas causas sem que ocorra uma mudança radical nos sistemas de conhecimento, dos valores e dos comportamentos gerados pela dinâmica de racionalidade existente, é impossível, visto que é fundada no aspecto econômico do desenvolvimento (LEFF, 2001, p.3).
\end{abstract}

Nas décadas de 1980 e 1990, a crescente confluência das vertentes economicista e ambientalista, conforme Jacobi (2005, p. 67) “deveu-se principalmente ao avanço da crise ambiental, por um lado, e ao aprofundamento dos problemas econômicos e sociais para a maioria das nações" (JACOBI, 2005, p. 67). Em tais décadas reforçou-se a importância de adotar esquemas integradores, em vista a degradação ambiental e à crescente desigualdade entre regiões que assumiam um lugar de destaque (JACOBI, 2005, p. 67).

Em 1988 em Buenos Aires, na Argentina, ocorreu o Seminário Latino-Americano onde algumas orientações sobre a Educação ambiental foram destacadas (PELICIONE, 1998):

\begin{abstract}
A Educação Ambiental deve fazer parte da política ambiental dos países; adaptarse às características culturais específicas das populações envolvidas no processo educativo; deve considerar o contexto de subdesenvolvimento dos países da América do Sul e se transformar num instrumento idôneo para a integração e o apoio mútuo entre as nações da região. Deve também salientar a necessidade de criação de um novo estilo de desenvolvimento que inclua crescimento econômico, igualdade social e conservação de recursos naturais, capaz de propiciar relações mais humanas, fraternas e justas entre os homens, e destes com o seu entorno natural, atingindo níveis crescentes de qualidade de vida (DIAS, 1992, p 13).
\end{abstract}

Segundo Jacobi (2005, p. 68) o que se observa é que 
[...] enquanto se agravavam os problemas sociais e se aprofundava a distância entre os países pobres e os industrializados, emergiram com mais impacto diversas manifestações da crise ambiental, que se relacionam diretamente com os padrões produtivos e de consumo prevalecentes (JACOBI, 2005, p. 68).

Com isso, o termo desenvolvimento sustentável carrega um conjunto de paradigmas para o uso dos recursos que visam suprir as necessidades do homem. Segundo Torresi (et al. 2010) este termo foi cunhado em 1987 no Relatório Brundtland da Organização das Nações Unidas que "estabeleceu que desenvolvimento sustentável é o desenvolvimento que satisfaz as necessidades do presente sem comprometer a capacidade das gerações futuras satisfazerem as suas próprias necessidades".

Torresi, (et al., 2010, p. 42) considera que, dessa forma, esse termo deve

[...] considerar a sustentabilidade ambiental, econômica e sociopolítica. Dentro da questão ambiental (água, ar, solo, florestas e oceanos), ou seja, tudo que nos cerca precisa de cuidados especiais para que continue existindo. Portanto, as sustentabilidades econômica e sociopolítica só têm existência se for mantida a sustentabilidade ambiental (TORRESI et al., 2010, p. 42).

Por certo, a proposição do desenvolvimento sustentável mostra-se pertinente sob certos aspectos e em determinados contextos, como quando se torna a chave que permite dar início a um diálogo entre os atores das áreas da economia, da política e do meio ambiente (SAUVÉ, 2005, p. 10).

Os anos de 1990, conforme Jacobi (2005) marcam mudanças significativas no debate internacional sobre os problemas ambientais, pois

A Conferência das Nações Unidas sobre o Meio Ambiente e o Desenvolvimento - Rio 92 - constitui-se um momento importante para a institucionalização da problemática ambiental, sendo que os temas da sustentabilidade e do desenvolvimento sustentável foram adotados como referenciais que presidiram todo o processo de debates, declarações e documentos formulados (JACOBI, 2005, p. 68).

Somada a isto, Lima (2003) destaca que

A realidade atual exige uma reflexão cada vez menos linear, e isto se produz na inter-relação dos saberes e das práticas coletivas que criam identidades e valores comuns e ações solidárias diante da reapropriação da natureza, numa perspectiva que privilegia o diálogo entre saberes (LIMA, 2003, p. 7).

Nesse sentido Sauvé (2005) complementa salientando que:

A educação ambiental não é, portanto, uma "forma" de educação (uma "educação para...") entre inúmeras outras; não é simplesmente uma "ferramenta" para a 
resolução de problemas ou de gestão do meio ambiente. Trata-se de uma dimensão essencial da educação fundamental que diz respeito a uma esfera de interações que está na base do desenvolvimento pessoal e social: a da relação com o meio em que vivemos, com essa "casa de vida" compartilhada. A educação ambiental visa a induzir dinâmicas sociais, de início na comunidade local e, posteriormente, em redes mais amplas de solidariedade, promovendo a abordagem colaborativa e crítica das realidades socioambientais e uma compreensão autônoma e criativa dos problemas que se apresentam e das soluções possíveis para eles (SAUVÉ, 2005, p.11).

Com isso, iniciou-se a busca por metodologias que atingissem o maior número de pessoas, estimulando-as sobre a necessidade de se conscientizar sobre o modo de como "cuida-se" do meio onde se vive. Neste ínterim, a escola veio a calhar. Conforme Loureiro (2005):

Ao pensarmos a educação, enquanto práxis social cujo fim é o aprimoramento humano naquilo que pode ser aprendido e recriado a partir dos diferentes saberes existentes em uma cultura, de acordo com as necessidades, possibilidades e exigências de uma sociedade, alguns problemas se explicitam no uso de abordagens sistêmicas (LOUREIRO, 2005, p. 23).

Tamaio (2000, p.4) faz entender-se, portanto, que a "educação ambiental é condição necessária para modificar um quadro de crescente degradação socioambiental, mas ela ainda não é suficiente”. Educação Ambiental para Tamaio (2000) se converte em

mais uma ferramenta de mediação necessária entre culturas, comportamentos diferenciados e interesses de grupos sociais para a construção das transformações desejadas". O educador tem a função de mediador na construção de referenciais ambientais e deve saber usá-los como instrumentos para o desenvolvimento de uma prática social centrada no conceito da natureza (TAMAIO, 2000, p. 4).

Neste ínterim Sorrentino (2005) acrescenta

A educação ambiental nasce como um processo educativo que conduz a um saber ambiental materializado nos valores éticos e nas regras políticas de convívio social e de mercado, que implica a questão distributiva entre benefícios e prejuízos da apropriação e do uso da natureza. Ela deve, portanto, ser direcionada para a cidadania ativa considerando seu sentido de pertencimento e coresponsabilidade que, por meio da ação coletiva e organizada, busca a compreensão e a superação das causas estruturais e conjunturais dos problemas ambientais (SORRENTINO, 2005, p. 13).

À Educação Ambiental cabe a tarefa, entre outras coisas, de reestabelecer a convivência no grupo. Lidar com problemas complexos, como os relativos ao ambiente, exige o máximo de informações, uma visão ampliada sobre a questão. Dessa forma, Reigada e Reis (2004) salientam que: 
Quanto mais informações tivermos, mais próximos da realidade estaremos e mais próximos de encontrar a solução, e quanto maior o número de pessoas trabalhando na solução dos problemas, maior a probabilidade de termos êxito na solução destes (REIGADA; REIS, 2004, p. 4).

Atualmente, necessita-se de novas ideias ousadas e imaginativas, pois se vive um momento de revolução, na qual a sociedade humana deve (re)aprender hábitos sustentáveis. Não se diz que o ser humano deve voltar a viver em cavernas e caçar para se alimentar. Mas sim, que o Homo sapiens necessita cuidar com os excessos alimentares, consumismo exagerado, e acima de tudo, carece respeitar o seu semelhante. Torresi et al. (2010) ressalta que:

A conservação do meio ambiente deve ser estar inserida em uma política de desenvolvimento do país, mas é importante enfatizar que ela não pode ser de apenas uma pessoa ou um governo. $\mathrm{O}$ meio ambiente deve ser um cuidado de todos com tudo. Os cidadãos devem estar permanentemente alertas para os perigos das ações mais inocentes que são realizadas no meio ambiente. A implementação de ações sustentáveis envolve atos e ações simples como ir a um supermercado, o uso racional de água nas residências, a manipulação adequada do lixo etc., mas deve envolver também atitudes radicais quanto ao consumismo exagerado (TORRESI et al., 2010, p. 12).

Desse modo, acredita-se que a educação ambiental nas escolas seja um importante caminho à conservação das espécies, pois, conforme Penin (2001, p.3) "na vivência diária em uma instituição escolar, as pessoas e os grupos que aí se formam, vão também produzindo novos modos de vida e assim, recriam a cultura geral” (PENIN, 2001, p.3). Assim como menciona Grosbaum (2001):

A escola, por meio de estudos e debates, assume a concepção de ensinoaprendizagem sociointeracionista, quer dizer: o conhecimento é construído pela interação do sujeito com o meio social, e a sua apropriação se efetiva por meio da articulação entre os conceitos cotidianos e científicos. A escola tem o papel central de promover a construção do conhecimento, garantindo ao aluno o acesso ao saber sistematizado e à formação de atitudes e habilidades, proporcionando condições para o exercício da cidadania plena e a construção de uma sociedade mais justa (GROSBAUM, 2011, p. 34).

Somado a isso, frisa-se que a educação ambiental ganha força quando a escola pode interagir em uma ação conjunta com a família, suas atividades religiosas, o clube, enfim, com toda a sociedade para a conscientização de que uma ação individual reflete no coletivo. 


\subsection{O Instituto Estadual São José}

Em meados de 1936, foi para o município de Soledade, no Estado do Rio Grande do Sul, a Ordem dos Frades Menores Capuchinhos, que criaram a entidade beneficente intitulada: Sociedade Literária São Boa Ventura, onde iniciaram suas atividades religiosas no município (PPP, 2014).

No ano seguinte foi aberta a escola Primária São José, particular para ambos os sexos. Em 1939, os freis Capuchinhos criaram o anexo a Escola Primária: o Ginásio São José. Já em 1944 funcionava regularmente o Curso de Admissão, com duração de um ano, onde os alunos aprovados poderiam ingressar no Curso Ginasial. A instalação solene do Ginásio São José deu-se em 15 de março de 1947, iniciando-se as aulas no mesmo dia. (PPP, 2014).

O grande batalhador que desde 1936 não mediu esforços para tornar o Ginásio São José uma realidade, foi também o seu primeiro diretor: Frei Clemente Nova Bassano. $\mathrm{Na}$ época de sua oficialização, o corpo docente da escola era assim formado: Frei Clemente, diretor, Fioravante Pedrassani, professor e secretário; João Provin, Etelvino Pedrassani, Davi Piussi e Renato Teixeira, professores (PPP, 2014).

O Ginásio São José permaneceu como Escola Particular com esse nome até 09 de agosto de 1945, quando, pelo decreto estadual número 17.415, foi transformado em Escola Estadual, com denominação de Ginásio Estadual de Soledade. No ano de 1949 deu-se início à edificação do prédio Ginásio São José, que foi concluído e inaugurado em dezembro de 1950. Trata-se do antigo prédio localizado na esquina da Av. Maurício de Cardoso com a rua Dr. Flores. De 1956 a 1974, anexo ao Ginásio São José, funcionou a Escola Técnica de Comércio Frei Clemente. (PPP, 2014).

A partir de 1972, o então Ginásio Estadual de Soledade passou a oferecer suas atividades no prédio construído pelo Estado, na Av. Pinheiro Machado, 526. Em 0704-2000, através de votação da comunidade escolar, foi oficializado, com o ato da Secretaria da Educação do Estado, número 0093, o Ginásio Estadual São José passando a denominar-se Instituto Estadual São José (I.E. São José) (PPP, 2014).

Atualmente, a escola conta com mais de 50 colaboradores, considerando professores, funcionários e gestores. Possui dois prédios de alvenaria, refeitório, laboratório de informática, sala de vídeo, biblioteca, laboratório de aprendizagem, laboratório de ciências, sala de leitura e duas quadras de esportes, sendo uma coberta.

Além disso, a filosofia da escola é:

Buscar uma ação educativa voltada para a integração da comunidade escolar, embasada no comprometimento, responsabilidade, solidariedade e conhecimento, possibilitando uma melhor qualidade de vida. Neste contexto destaca-se: Comprometimento e responsabilidade como consigo mesmo, com o outro e com o grupo, tendo consciência dos seus atos no meio em que vive, na sociedade buscando transformá-la. Solidariedade como desenvolvimento da afetividade, preocupando- 
se com as questões humanas e sociais. Conhecimento como aprimoramento do saber pessoal, universal e científico, a construção do conhecimento e da aprendizagem. (PPP, 2014, p. 9).

\section{2. "Ecoações"}

A oficialização da Educação Ambiental no Brasil aconteceu através da lei federal de $\mathrm{n}^{\circ}$ 6.938, sancionada a 31 de agosto de 1981, que criou a Política Nacional do Meio Ambiente (PNMA). Apesar do atraso em relação às recomendações da Conferência de Estocolmo, esta lei foi promulgada graças ao trabalho e empenho de setores da sociedade como partidos de esquerda, ONGs, ambientalistas e acadêmicos (MORADILLO; OKI, 2004, p.56).

No nível governamental federal, vários órgãos estiveram envolvidos com a implementação da educação ambiental, seja na vertente ambiental ou na área educacional, através de vários programas e diretrizes como o PRONEA (Programa Nacional de Educação Ambiental), DEA (Diretrizes de Educação Ambiental), o PEPEA (Programa de Estudos e Pesquisa em Educação Ambiental). Outra importante ação no nível educacional foi a inclusão da questão ambiental na Lei de Diretrizes e Bases da Educação Brasileira (LDB/96), que passou a considerar a compreensão do ambiente natural como fundamental para a educação básica. A inclusão da área de Meio Ambiente como um dos temas transversais nos Parâmetros Curriculares Nacionais ( $\mathrm{PCNs}$ ) encontra-se enfocada no seguinte trecho desse documento que traz orientações para o trabalho do professor: "O trabalho pedagógico com a questão ambiental centra-se no desenvolvimento de atitudes e posturas éticas e, no domínio de procedimentos, mais do que na aprendizagem de conceitos". Mais recentemente, o Senado aprovou a lei federal 9.795, em 27 de abril de 1999, que tem como objetivo oficializar a presença da Educação Ambiental em todas as modalidades de ensino (MORADILLO; OKI, 2004, p. 56).

A educação ambiental é orientada por uma racionalidade ambiental, transdisciplinar, pensando, como Sorrentino (et al. 2005, p.15) "o meio ambiente não como sinônimo de natureza, mas uma base de interações entre o meio físico-biológico com as sociedades e a cultura produzida pelos seus membros" (SORRENTINO et al. 2005, p. 15).

Segundo Loureiro (2005, p. 46) a educação ambiental integra propostas educativas "oriundas de concepções teóricas e matrizes ideológicas distintas, sendo reconhecida publicamente, no Brasil, como de inegável relevância para a construção de uma perspectiva ambientalista de mundo e de sociedade" (LOUREIRO, 2005, p.46).

Santos (2000) expõe que:

A Educação Ambiental movimenta-se num discurso de valorização da solidariedade como um processo em que o conhecimento apreendido pode ser 
considerado, sempre inacabado, de nos tornarmos capazes de reciprocidade através da construção e do reconhecimento da intersubjetividade. A ênfase na solidariedade converte a comunidade no campo privilegiado do conhecimento emancipatório (Santos, 2000, p. 5).

Numa perspectiva dialética, "sociedade e natureza se fusionam pela práxis histórica" (SCHMIDT, 1983, p. 7), cuja unidade não pode ser confundida com a diluição de uma dimensão na outra. Com isso Loureiro (2005, p. 13) destaca:

[...] cumpre ter presente que a humanidade não se constitui como unidade homogênea e que as condições decorrentes da atuação humana no ambiente são definidas em função de cada modo de vida social, em interação com as condições ecológicas de sustentação. A visão que o marco teórico emancipatório em Educação Ambiental tem da humanidade é que esta é a unidade dialética com a natureza, em que os sujeitos são pensados concretamente e não abstratamente (LOUREIRO, 2005, p. 13).

Tristão (2005, p.45) sugere que:

É interessante pensar em abordagens educativas menos cobradoras de uma "consciência racional" nas interações socioambientais e nas práticas sociais cotidianas. Nesse caso, a formação de comunidades interpretativas poderia deslanchar uma abordagem racionalmente menos exigente e mais expressiva no campo da comunicação humana e menos dogmática ao analisar coletivamente por que motivo as sociedades agem de determinadas maneira e não de outras em relação ao meio ambiente, desenvolvendo um trabalho educativo de sensibilidade para um saber solidário de conhecimento-emancipação (TRISTÃO, 2005, p. 45).

\section{A Educação Ambiental, para Moradillo e Oki (2004, p.2)}

deve proporcionar experiências que possibilitem colocar as pessoas em contato direto com o mundo e sensibilizá-las para os ecossistemas que as envolvem; discutir a importância do ambiente para a saúde e o bem estar do homem e para o exercício da cidadania; avaliar o desenvolvimento econômico aliado à degradação ambiental e à qualidade de vida e desenvolver no educando o sentido ético-social diante dos problemas ambientais (MORADILLO; OKI. 2004, p. 2).

Reigota (1991, p. 4) tornando a participação uma realidade, pela Educação o "indivíduo pode vencer o distanciamento que a vida moderna traz, além de trabalhar valores fundamentais, sua importância na sociedade, discussão e questionamento" (REIGOTA, 1991, p. 4). Ainda informa que

A Educação Ambiental popular tem uma tradição pedagógica, mas também é voltada para o avanço das camadas populares na busca por qualidade de vida, democracia e cidadania. Visando a coletividade, busca solucionar problemas sociais e ambientais, recuperando o potencial crítico dos movimentos ecológicos. Para este avanço qualitativo ser significativo, ações educativas ambientais que 
criem oportunidades de participação efetiva dos envolvidos são fundamentais. Participação não se esgota na "chamada" dos sujeitos para acompanhar ações sociais, mas exige experiência participativa (REIGOTA, 1991, p. 6)

Em busca de despertar o interesse para a importância de ações ambientalmente corretas, realizou-se uma pesquisa de campo na escola, entrevistando diversos setores da comunidade escolar, como alunos, professores, funcionários e gestores. Primeiramente, desejou-se conhecer o que a escola já possuía de ações ecologicamente corretas, e, em seguida, solicitou-se sugestões de ações para tornar a escola Instituto Estadual São José mais ecologicamente correta (Anexo 1).

Como resultado obteve-se:

1) O que a escola já possui de ações ecologicamente corretas:

1) Lixeiras coloridas para separação de resíduos;

2) Uniforme;

3) Horta vertical;

4) Jardim com árvores;

5) Xerox com folhas reaproveitadas;

6) Estufa de mudas nativas;

2) Sugestões dos alunos, professores, funcionários e gestores para tornar a escola Instituto Estadual São José mais ecologicamente correta:

1) Reutilizar a água da chuva para limpeza da escola;

2) Recado para fechar as torneiras dos banheiros / trocar as torneiras dos banheiros;

3) Recado para não desperdiçar alimentos;

4) Plantar mais árvores;

5) Desligar as luzes da sala de aula na saída para economizar energia;

6) Composteira e horta;

7) Fazer papel reciclado;

8) Palestras sobre o meio ambiente;

9) Tópicos e mensagens sobre o meio ambiente no mural;

10) Reaproveitar livros que seriam jogados fora para recorte;

11) Multa para quem jogar lixo no chão;

12) Colocar a separação de resíduos em todas as repartições da escola;

13) Trabalho de conscientização de pais, professores, funcionários e alunos;

14) Os alunos fazerem a limpeza do terreno da escola coletando os materiais recicláveis;

15) Utilizar a energia solar; 
16) Arrecadar e vender materiais recicláveis, destinando o dinheiro para melhorias na escola;

3) Possíveis de execução imediata:

1) Recado para fechar as torneiras dos banheiros;

2) Recado para não desperdiçar alimentos;

3) Desligar as luzes da sala de aula na saída para economizar energia;

4) Palestras sobre o meio ambiente;

5) Tópicos e mensagens sobre o meio ambiente no mural;

6) Reaproveitar livros que seriam jogados fora para recorte;

7) Trabalho de conscientização de pais, professores, funcionários e alunos;

4) Possíveis de execução a médio e longo prazo:

1) Reutilizar a água da chuva para limpeza da escola;

2) Trocar as torneiras dos banheiros;

3) Plantar mais árvores;

4) Composteira e horta;

5) Fazer papel reciclado;

6) Multa para quem jogar lixo no chão;

7) Colocar a separação de resíduos em todas as repartições da escola;

8) Os alunos fazerem a limpeza do terreno da escola coletando os materiais recicláveis;

9) Utilizar a energia solar;

10) Arrecadar e vender materiais recicláveis, destinando o dinheiro para melhorias na escola.

A primeira atividade realizada foi transmitir aos estudantes do $6^{\circ}$ ano do Ensino Fundamental da escola, vídeos educativos do Instituto Akatu (AKATU, 2015) no intuito de estimular a conscientização do quão importante é cada um fazer a sua parte, conservando o ambiente, para o bem estar de todos.

Em seguida, os estudantes foram instigados a criar um recado a ser fixado nos banheiros da escola, com um recado ecologicamente correto. Então, utilizando o símbolo da escola, que é uma coruja, eles construíram o recado: "Feche as torneiras após lavar as mãos" e fixaram nos banheiros da escola.

Conforme Reigada e Reis (2004, p.6) "a aprendizagem significativa é obtida com a integração do pensamento, sentimento e ação com a estrutura cognitiva do aprendiz" (REIGADA; REIS, 2004, p. 6). Para ocorrer a aprendizagem de forma significativa, o ensino deve ser planejado de modo a facilitá-la e incentivar as experiências afetivas 
positivas. Sendo assim, o conhecimento passa a ter um significado real, um por que na realidade em que as crianças se encontram.

\section{CONCLUSÃO}

Segundo Saviani (1994, p.12),

A Educação é a forma que o homem tem de se apropriar da produção de conhecimento gerado ao longo da história pela humanidade, pela cultura, o que ele considera uma "segunda natureza", pela história dos homens, que se formam como indivíduos e que produzem também coletivamente, novos conhecimentos. Neste sentido, cada indivíduo terá instrumentos para criticar a realidade e perceber e descobrir como participar das mudanças pelas quais terá condições de lutar (SAVIANI, 1994, p.12).

Nesse sentido, Reigada e Reis (2004, p.7) afirmam

Sendo uma dimensão da educação, a Educação Ambiental é um processo educativo que visa formar cidadãos éticos nas suas relações com a sociedade e com a natureza. Durante a formação, cada indivíduo é levado a uma reflexão de seus comportamentos e valores pela aquisição de conhecimentos, compromisso e responsabilidade com a natureza e com as gerações futuras (REIGADA; REIS, 2004, p. 7)

A educação ambiental é a ponte que interliga o hoje ao mundo que se almeja. Sabe-se que atualmente o planeta Terra está sendo esgotado de seus recursos naturais e ações imediatas para minimizar este contrassenso necessitam ser executadas. Com isso, estimulando cada estudante a tomar consciência da importância das suas ações, é possível estabilizar a degradação caótica que se enfrenta, uma vez que partirá do individual ao bem coletivo.

\section{REFERENNCIAS}

AKATU. Consumo consciente para um futuro sustentável. Disponível em: <http:// www. akatu.org.br>. Acesso em: 25, maio 2015.

BRASIL. Lei No 9.394, de 20 de dezembro de 1996. Estabelece as diretrizes e bases da educação nacional. In: SENADO FEDERAL. Legislação Republicana Brasileira. Brasília, 1996. Disponível em: Acesso em: 14 nov. 2015.

CARVALHO, I. C. M. Educação ambiental: a formação do sujeito ecológico. 2.ed. São Paulo: Cortez, 2006.

DIAS, G.F. Educação ambiental: princípios e práticas. São Paulo, Gaia, 1992. 
ENGUITA, M.F. La Escuela a examerr. um análisis sociológico para educadores y outras personas interessadas. Madrid: Pirâmide, 1995.

GROSBAUM, M. W. Como promover o sucesso da aprendizagem do aluno e sua permanência na escola?. In: Progestão. MACHADO, M. A. M. (coord.). Módulo IV. Brasília: CONSED, 2001.

HERCULANO, S. Do desenvolvimento (in)suportável à sociedade feliz. In: GOLDEMBERG, M. (Org.). Ecologia, ciência e política. Rio de Janeiro: Revan, 1992.

JACOBI, Pedro Roberto. Educação ambiental, cidadania e sustentabilidade. Cadernos de Pesquisa, n. 118, março/ 2003 Cadernos de Pesquisa, n. 118, p. 189-205, março/ 2003.

JACOBI, Pedro Roberto. Educação Ambiental: o desafio da construção de um pensamento crítico, complexo e reflexivo. Educação e Pesquisa, São Paulo, v. 31, n. 2, p. 233-250, maio/ ago. 2005.

LEFF, E. Epistemologia ambiental. São Paulo: Cortez, 2001.

LIMA. G.F. da C. Educação ambiental crítica: do sociambientalismo às sociedades sustentáveis. Educação e Pesquisa. São Paulo, v.35. n.1. p. 145-163. Jan/abril 2009.

LOUREIRO, Carlos Frederico Bernardo. Complexidade e dialética: contribuições à práxis política e emancipatória em educação ambiental. Educação e Sociedade, Campinas, v. 26, n. 93, p. 1473-1494, Set./Dez. 2005.

MORADILLO, E. F. de; OKI, M. C. M. EDUCAÇÃO AMBIENTAL NA UNIVERSIDADE: CONSTRUINDO POSSIBILIDADES. Química Nova, V. 27, n. 2, p. 332-336, 2004.

PELICIONE, M.C.F. Educação ambiental, qualidade de vida e sustentabilidade. Saúde e Sociedade. v. 7. p. 19-31. 1998.

PENIN, Sonia Teresinha de Sousa. Como articular a função social da escola com as demandas da comunidade?. In: Progestão. MACHADO. M. A. M (coord.). Módulo 1. Brasília: CONSED, 2001.

PROJETO Político Pedagógico da escola Instituto Estadual São José, 2014.

REIGADA. C.; M. F. C. T. REIS. Educação ambiental para crianças no ambiente urbano: uma proposta de pesquisa-ação. Ciência \& Educação, v. 10, n. 2, p. 149-159, 2004.

REIGOTA, M. Fundamentos teóricos para a realização da educação ambiental popular. Em Aberto, Brasília, v.10, n. 49, p. 34-41, jan./mar. 1991.

SADER, E. A ecologia será política ou não será. In: GOLDENBERG, M. org. Ecologia, ciência e política: participação social, interesses em jogo e luta de ideias no movimento ecológico. Rio de Janeiro, Revan, 1992, p. 135-42.

SANTOS, B. de S. A crítica da razão indolente: A crítica da razão indolente contra o desperdício da experiência. 2000. 
SAUVÉ, Lucie. Educação Ambiental: possibilidades e limitações. Educação e Pesquisa, São Paulo, v. 31, n. 2, p. 317-322, maio/ago. 2005.

SAVIANI, D. Sobre a natureza e especificidade da educação. In: SAVIANI, D. Pedagogia histórico-crítica: primeiras aproximações. São Paulo: Cortez, 1994.

SCHMIDT, A. El concepto de naturaleza en Marx. 4. ed. Madrid: Siglo XXI, 1983.

SORRENTINO, Marcos. et al. Educação ambiental como política pública. Educação e Pesquisa, São Paulo, v. 31, n. 2, p. 285-299, maio/ago. 2005.

TAMAIO, I. A Mediação do professor na construção do conceito de natureza. Campinas, 2000. Dissert. (Mestr.) FE/Unicamp.

TORRESI, et al. O que é sustentabilidade? Química Nova. v. 33 n.1. São Paulo. 2010.

TOZONI-REIS, Marília Freitas de Campos. Educação ambiental: natureza, razão e história. Campinas: Autores Associados, 2004.

TRISTÃO, Martha. Tecendo os fios da educação ambiental: o subjetivo e o coletivo, o pensado e o vivido. Educação e Pesquisa, São Paulo, v. 31, n. 2, p. 251-264, maio/ago. 2005.

\section{ANEXOS}

\section{Anexo 1 Questões da pesquisa de campo}

Pesquisa de campo para elaboração do artigo final da pós-graduação em Educação Ambiental, EAD Barão de Mauá, da professora Letícia Hoehne.

1) Cargo na escola:

2)Sexo: ( )Feminino ( )Masculino

3) Idade: （）10 a 15 anos （ )16 a 20 anos （）21 a 30 anos （ )mais de 31 anos

4) Quais atividades ecologicamente corretas a escola I.E.São José realiza/possui?

5) Quais sugestões você indica para tornar a escola I.E.São José mais ecologicamente correta? 